\title{
Web Cartography going public: Developing a Massive Open Online Course (MOOC) for cartographic prosumers
}

\author{
Lorenz Hurni $^{\text {a, *, Charalampos Gkonos }}{ }^{\text {a }}$, Hans-Rudolf Baer ${ }^{\text {a }}$ \\ ${ }^{a}$ ETH Zurich, Institute of Cartography and Geoinformation, Stefano-Franscini-Platz 5, 8093 Zurich, Switzerland, lhurni@ethz.ch, \\ gkonosch@gmail.com and hbaer@ethz.ch \\ * Corresponding author
}

Keywords: MOOC for Cartography, Course Development, Course Evaluation, Web Cartography

Abstract:

The science of cartography has evolved significantly during the last years. Major developments have been achieved in the specific areas of output media, map production technologies and dissemination channels. The existence of several freely available web-mapping tools (e.g. JavaScript mapping libraries) encourages a broader community of users to produce web-maps and visually represent research results and data. Despite the obvious advantages of promoting the importance of cartography to a wider audience, the difficulty of conveying, acquiring and applying specialised cartographic knowledge might discourage this new global "crowd" of prosumers (= at the same time producer and users of maps).

A modern and promising approach in reaching those target groups is through a Massive Open Online Course (MOOC). MOOCs belong to a relatively new Technology Enhanced Learning (TEL) group of educational approaches, which an increasing number of universities try to integrate in their teaching. The main objectives of those courses is to disseminate knowledge through the sharing of free high-quality learning materials, to produce new knowledge through students' interactions with the course platform, and to enable research on education and learning. In spite of the numerous advantages offered by MOOCs, their number remains relatively small within the field of cartography, compared to other scientific areas (e.g. Business \& Management).

Part 1

\begin{tabular}{|c|c|c|}
\hline Week 1 & Maps on the Web & 1.1 Motivation and Purpose \\
\hline & & 1.2 History of the Web Browser \\
\hline & & 1.3 The Language of the Web \\
\hline Week 2 & Layout and Design & 2.1 HTML Elements \\
\hline & & 2.2 Stylesheets \\
\hline & & 2.3 Classical Map Layout \\
\hline Week 3 & Programming with Maps & 3.1 Map Programming \\
\hline & & 3.2 Introduction to JavaScript \\
\hline & & 3.3 Learning More JavaScript \\
\hline Week 4 & Interacting with Maps & 4.1 Interactions and Events \\
\hline & & 4.2 The Document Object Model DOM \\
\hline & & 4.3 More Interactions \\
\hline Week 5 & The Graphics of Maps & 5.1 Graphics Elements \\
\hline & & 5.2 Graphics Algorithms \\
\hline & & 5.3 Graphics For the Browser \\
\hline
\end{tabular}

Part 2

\begin{tabular}{|c|c|c|}
\hline Week 1 & Detailed World Map & 1.1 The Interminable Map \\
\hline & & 1.2 Mapping Libraries \\
\hline & & 1.3 Populated Maps \\
\hline Week 2 & Maps from Data & 2.1 Web-Friendly Data Formats \\
\hline & & 2.2 Geographic Vector Data Formats \\
\hline Week 3 & Web Maps Approach & 3.1 The Design of the D3 Library \\
\hline & & 3.2 Principle of Data Binding \\
\hline & & 3.3 D3 Mapping Examples \\
\hline Week 4 & Exploring the Planet & 4.1 Mapping the Planet \\
\hline & & 4.2 Basics of 3D Graphics \\
\hline & & 4.3 The Cesium Globe \\
\hline Week 5 & Art of Coding & 5.1 Building User Interfaces \\
\hline & & 5.2 Creating Web Apps \\
\hline & & 5.3 Writing Good Code \\
\hline
\end{tabular}

Table 1: Course structure and content 
In order to disseminate the missing cartographic knowledge by means of state-of-the-art online and distance learning tools, a project group at the Institute of Cartography and Geoinformation (IKG) of ETH Zurich has initiated and developed a new introductory MOOC on Web Cartography since 2017. It is to our knowledge the first introductory MOOC on Web Cartography addressing both cartographers and non-cartographers. Based on our experience in the regular university courses and on numerous external requests for support in web cartography, we want to provide the MOOC students with the theoretical background, technical knowledge and practical skills to successfully produce interactive cartographic web applications. The course is divided in two parts. Part 1 deals with web technologies to create interactive web maps. It first describes the functioning of JavaScript mapping libraries and shows how animations and interactive elements can be added. Part 2 deepens the knowledge on JavaScript mapping libraries, shows how map data can be processed and manipulated, gives an overview of web-friendly data formats and presents powerful visualization components and a data-driven approach to DOM manipulation. Furthermore, the basics of 3D graphics are introduced. Finally, the web map application is completed with a user-friendly interface. Table 1 gives an overview of the course content structured in modules.

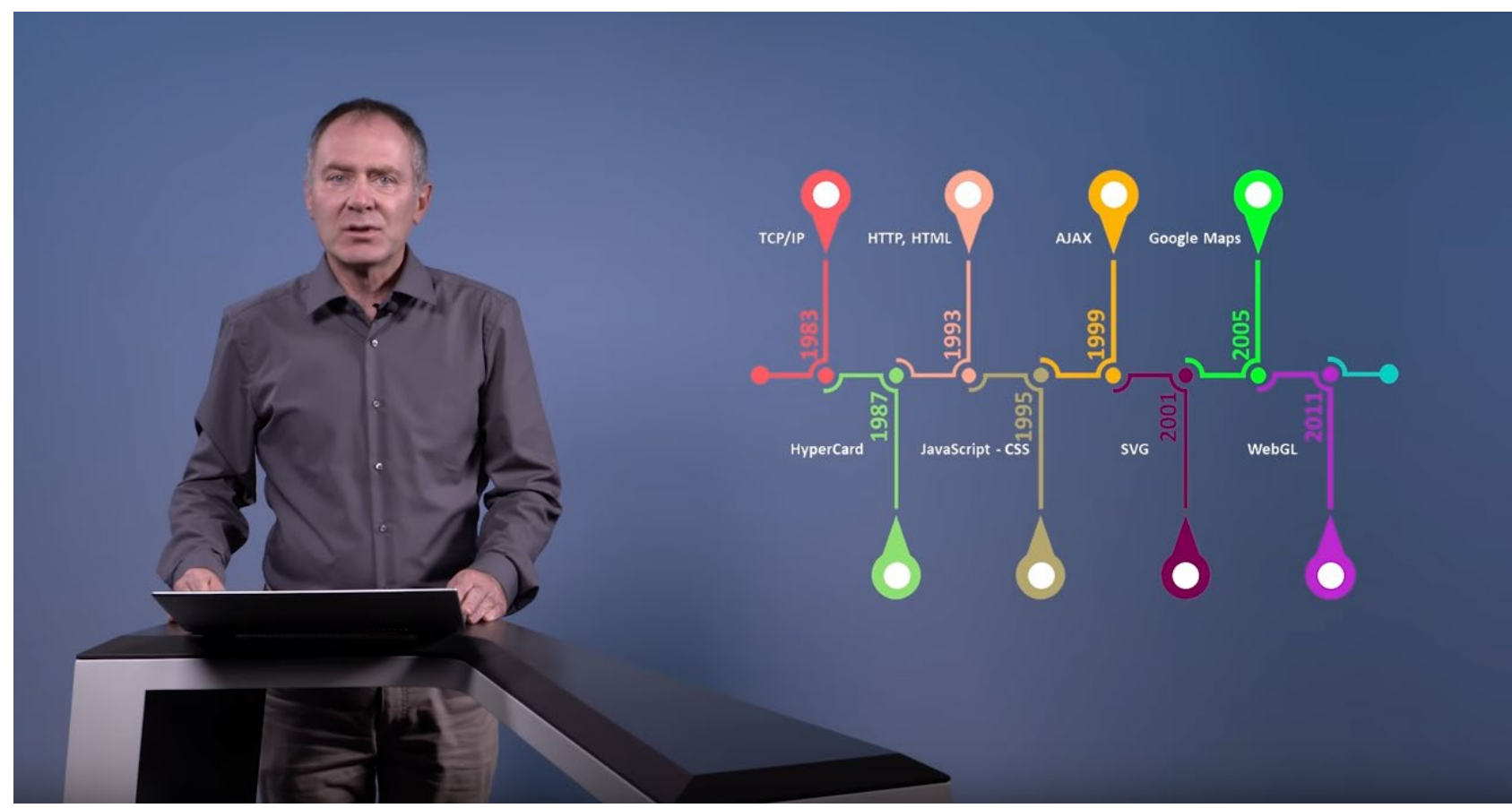

Figure 1. Instance of a MOOC lecture from the course "Introduction to Web Cartography: Part 1"

The course is based on 9 different didactic pillars:

1. The course follows a competence-based design approach that focuses on the outcomes of the learning process.

2. The overall learning targets and objectives are defined at the beginning of each course week, and refer to course lessons as well as to exercises. Even for each single lesson, the specific learning content is presented at the beginning and the student is accordingly guided step-by-step through the lesson.

3. A Pedagogical approach of "Extreme Apprenticeship" has been chosen. It comprises various exercises that offer the opportunity for actual practice, as well as continuous feedback from the advisor to the learner during the supervised course phase.

4. A learning plan is offered for each participant. If necessary, the plan can be individually adjusted by supplying scheduling assistance from the course team. The course can also be attended in a self-paced mode, outside of the official course phases.

5. The professor addresses the student directly under talking-head videos (Fig. 1).

6. Nevertheless, there are opportunities for social networking by setting up a space to foster social interaction and frequent contact among learners, and with the supervisors.

7. It was decided to use shorter videos, which are proven to be more engaging, leaving enough time to deepen the knowledge, i.e. by rewinding the video, as well as for the carefully adapted exercises.

8. The examples were chosen in order that they can be understood regardless of the cultural background.

9. During the supervised course phase, feedback was given by the course team after each e-assessment question 
In the first supervised phase, the course was attended by approximately 1000 students. As generally in MOOCs we could observe an effect of rather rapid increase of enrolment, but also a similar decrease of participation and power of endurance of the students. Only about 20 students have finally obtained a certificate of successful attendance. The feedback was generally good. The effort to provide personal feedback to the students was however rather high, and the exchange would have been easier in a personal classroom environment.

Since the beginning of the course data have been collected to let us analyse the influence of our approach to the teaching experience as well as to identify its advantages and disadvantages. The produced knowledge can help us evaluate the followed methodology as well as to make suggestions for the future design of geospatial MOOCs and their impact on education and training in cartography.

Access to course:

Part 1: https://www.edx.org/course/introduction-to-web-cartography-part-1-1

Part 2: https://www.edx.org/course/introduction-to-web-cartography-part-2 